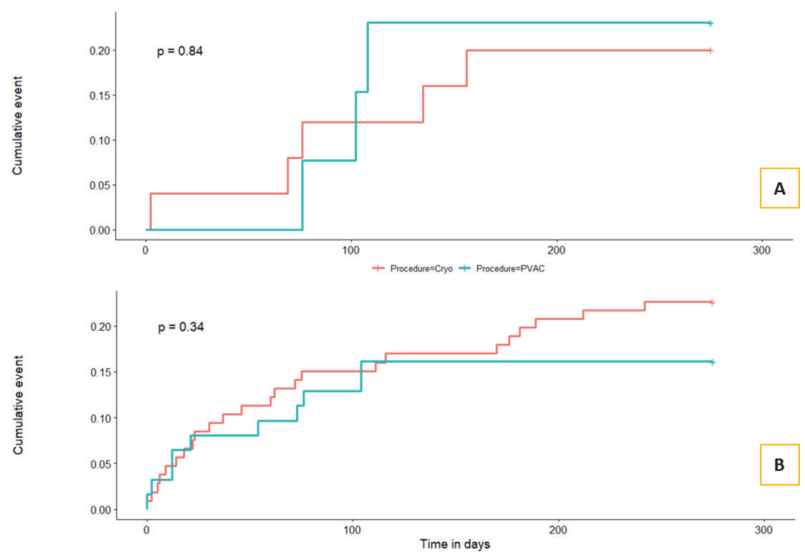

Abstract 99 Figure 1 Kaplan-Meier plots showing arrhythmia recurrence following ablation for persistent AF (panel A) and paroxysmal AF (panel B) with cryoballoon and PVAC after a 90-day blanking period

Abstract 99 Table 1 Patient demographics, procedural characteristics and outcomes for cryoballoon and PVAC cases. Values presented as mean \pm SD or $\mathrm{n}(\%)$. PVI= pulmonary vein isolation

\begin{tabular}{|c|c|c|c|}
\hline & $\begin{array}{l}\text { Cryoballoon } \\
n=131\end{array}$ & $\begin{array}{l}\text { PVAC } \\
n=75\end{array}$ & p-value \\
\hline Age/years & $59.5 \pm 10.6$ & $61.7 \pm 9.7$ & 0.64 \\
\hline Male & $88(67.2)$ & $49(61.3)$ & 0.80 \\
\hline Paroxysmal AF & $106(78.6)$ & $62(82.7)$ & 0.34 \\
\hline $\begin{array}{l}\text { Cardiovascular risk factors } \\
\text { Hypertension } \\
\text { Diabetes } \\
\text { Ischaemic heart disease } \\
\text { Cerebrovascular disease } \\
\text { Heart failure } \\
\text { Dyslipidaemia } \\
\end{array}$ & $\begin{array}{l}79(60.3) \\
19(14.5) \\
45(34.4) \\
0(0) \\
1(0.8) \\
16(12.2)\end{array}$ & $\begin{array}{l}43(57.3) \\
16(21.3) \\
22(29.3) \\
1(1.3) \\
0(0) \\
10(13.3)\end{array}$ & $\begin{array}{l}0.58 \\
0.24 \\
0.62 \\
- \\
- \\
0.71\end{array}$ \\
\hline Left atrial diameter/cm & $4.1 \pm 0.7$ & $3.9 \pm 1.0$ & 0.69 \\
\hline Procedure time/mins & $126.7 \pm 24$ & $117.4 \pm 30$ & 0.79 \\
\hline PVI success & 127 (96.9) & $74(98.7)$ & 0.88 \\
\hline $\begin{array}{l}12 \text { month success } \\
\text { Paroxysmal } \\
\text { Persistent }\end{array}$ & $\begin{array}{l}78 / 103(75.7) \\
18 / 24(75.0)\end{array}$ & $\begin{array}{l}48 / 61(78.6) \\
10 / 12(83.3)\end{array}$ & $\begin{array}{l}0.99 \\
0.80\end{array}$ \\
\hline
\end{tabular}

Abstract 99 Table 2 Observed complications for cryoballoon and PVAC cases. CVA $=$ cerebrovascular accident. Values presented as $n$ $(\%)$

\begin{tabular}{|c|c|c|c|}
\hline Complications & $\begin{array}{l}\text { Cryoballoon } \\
n=131\end{array}$ & $\begin{array}{l}\text { PVAC } \\
n=75\end{array}$ & p-value \\
\hline $\begin{array}{l}\text { Total } \\
\text { Vascular } \\
\text { Pericardial effusion } \\
\text { Air embolus } \\
\text { Phrenic palsy } \\
\text { Migraine } \\
\text { CVA } \\
\text { Pulmonary oedema } \\
\text { Leg numbness } \\
\text { Death }\end{array}$ & $\begin{array}{l}3(2.3) \\
0 \\
0 \\
1 \\
1 \\
0 \\
0 \\
0 \\
1 \\
0\end{array}$ & $\begin{array}{l}1(1.3) \\
1 \\
0 \\
0 \\
0 \\
0 \\
0 \\
0 \\
0 \\
0\end{array}$ & 0.84 \\
\hline
\end{tabular}

PVAC case requiring surgical intervention. One case each of phrenic nerve palsy, right leg numbness (due to local infiltration of local anaesthetic around the femoral nerve) and air embolism were associated with cryoablation. All resolved within hours, did not require intervention and did not delay discharge. No long-term sequelae were seen.

Conclusions PVAC and cryoballoon AF ablation appear equally efficacious with similar procedure times in an unselected population. Both were associated with a low adverse event rate.

Conflict of Interest nil

\section{DRIVE-BY PHYSIOLOGY SERVICES: A NOVEL MODEL FOR THE COVID-19 ERA}

Roshan Xavier, Nicola Montalbano, Tuan Chua. Royal Surrey County Hospital NHS Foundation Trust, Guildford, UK

10.1136/heartjnl-2021-BCS.99

The COVID-19 pandemic has led to unprecedented challenges for cardiac diagnostics and follow-up. Whilst the BHRS recommended remote device follow-up wherever possible, this is not always feasible. In addition, continuing diagnostic services including Holter monitoring was necessary to support the telephone-clinic based outpatient Cardiology service operating at the height of the pandemic. The physiology service at our district general hospital carried out 3494 device checks and 2762 ambulatory Holter monitors last year. We describe a novel model implemented here to continue providing essential cardiac investigations and device follow-up whilst minimising risk of COVID transmission.

A drive-by unit was set up within the hospital car park and specifically delineated parking spaces were allocated for patients to park with the patient remaining in the vehicle at all times. At the appointment time, they are called forward. To fit ambulatory Holter monitors, a PPE-donned physiologist passes over the Holter pack containing both the monitor and visual instructions on applying it. Assistance is provided via telephone if necessary. Return of the monitor is performed in a similar manner.

For device checks, the header is passed over to the patient suitably protected. The patient places the header over the site of the device for the duration of the check following which it is returned via the window. The device site is inspected visually where appropriate through the window. Our experience suggests that the diagnostic value of self-applied Holter monitors have been comparable to that of physiologist-applied monitors. To the end of August 2020, 850 device checks had been carried out and 557 Holter monitors had been dispensed. Dispensing the Holter monitors in this manner has resulted in a very high diagnostic accuracy with very few non diagnostic recordings on patient-applied Holters. Patient feedback in comparing experiences to the in-hospital pacing clinic have been very positive. This demonstrates that such a model is feasible without compromising clinical care whilst reducing face to face patient contact and subsequent likelihood of COVID-19 transmission.

Conflict of Interest Nil 